\title{
Effects of Managing Diversity in the Work Place
}

\author{
Dr. Cross Ogohi Daniel \\ Department Of Public Administration/Banking and finance, Nile University Of Nigeria, Abuja
}

\begin{abstract}
Diversity management is an all-inclusive work strategic intervention aimed at increasing every individual's potential to contribute to the realization of the organization's goals and objectives through exploit on individual talents and differences within a diverse workforce. Managing interpersonal relationships within a diverse workforce environment offers a number of tasks related to changes in the social, legal and economic landscape, individual expectations and values as well as the inevitable change in organizational culture. Whether or not organizations are effective in managing diversity are a function of senior managements' commitment, and the perceived centrality of diversity management by all those who populate the organisation's workspace. Above all it should be clear to all employees, irrespective of race, gender, or vocational/professional status, that each and every one of them has something of value to contribute towards the realization of the organisation's mission and goals. It is crucial to determine clear and manageable success indicators, focusing not only on compliance with legal obligations to include and/or increase the number of employees from the underrepresented and designated groups, but also on strategic intervention strategies to be used to promote and nurture individual talent and potential toward the realization of both individual aspirations and organizational goals re-quality patient outcomes.
\end{abstract}

Keywords: Managing Diversity, Workforce, Workplace and Organisation

DOI: $10.7176 / \mathrm{EJBM} / 11-5-05$

\subsection{Introduction}

Diversity is said to be an understanding, recognition and acceptance of individual differences irrespective of their race, gender, age, class, ethnicity, physical ability, and race. Sexual orientation, spiritual practice and so on. Also supports this view by adding that each individual is unique but also share any number of environmental or biological characteristics. Workplace diversity management broadly as a systematic and planned commitment by the organization to recruit, reward and promote a heterogeneous mix of employees. Diversity in this format was adopted by different countries, more so in the Western world. The concept was preceded by other diversity programs like affirmative action and equal employment opportunities.

Diversity is aimed at harnessing these differences which will create a productive environment in which everybody feels valued and where their talents are fully utilized though which organizational goals are met. Most organizations in their own perspective, adopt diversity at their workplace or organisation to become more creative and open to change. Increasing and improving workplace diversity has become an important issue for management in the recent years due to the recognition of how in the workplace is changing. Since managing diversity still remains a challenge in organisations, managers tend to learn managerial skills needed in a multicultural working environment and prepares themselves to teach others within their organizations to value cultural differences and treat all employees with dignity. For some business leaders and managers point of view, diversity is a big challenge to them although it knows no organizational boundary and has no limitations.

Griffin \& Moorhead (2014) explained that having a diverse workforce needs managers to recognize and manage the diverse attribute that occur among the employees in the organization. On these grounds, organizations are aiming to become more diversified in order to gain competitive advantage by becoming more creative, innovative and open to useful change.

Human resource is an important benefit for many organizations, and as such, having a diversified workforce is a basic concern for most organizations. Although, it has become essential for organizations to hire a diversified workforce, at the same time, it has become quite tasking for organizations with expanding diversified workforce to reap the profits of diversity while managing its possible disruptive effects (Kreitz, 2008; Saxena, 2014). Organizations are familiar with the fact that it is through the cooperative effort of its diversified workforce that monetary assets are yoked to achieve organizational goals.

For organizations to attain its goals, the skills, knowledge, attitude and efforts of its workforce have to be sharpening occasionally to enhance the effectiveness of its workforce and to enable them to meet greater challenges. Organizations are made up of individuals and without it in the workplace; organizations cannot achieve its goals (Mullins, 2010). For this reason, the management of its human resources is also a crucial issue for organizational leaders (Saxena, 2014).

However today respect for diversity is not simply tolerance of conflicting primary loyalties but extends to ensure differences in thought patterns, lifestyles, mannerisms and mind-sets (World Bank 2002) 


\section{Statement of the Problem}

Managers find it difficult in knowing the factors that contribute to effective diversity management or the exact leadership tasks that can be achieved to effectively and efficiently deal with issues related to workplace diversity. In recent years Diversity Management and workforce diversity have been substantial and as such have forced companies to embrace these concepts in their companies with the aim of increasing productivity and profit

Today, one of the many challenges that accompany increasing diversity is the widening range of employees ${ }^{\text {ee }}$ needs, which employers are meeting with such benefits as flexitime, job-sharing, telecommuting, and child and elder care programs. If diversity is not handled properly it can easily turn into a losing situation for all involved, leading to demoralization.

However, this study attempted to fill the gap of knowledge by promoting a more proactive effort that creates a workplace that would encourage employers to create diversity awareness and seek to build mentorship programs that would allow a more inclusive succession planning for women and minority groups.

\section{OBJECTIVE OF THE STUDY}

The general purpose of the study is to examine the effects of managing diversity in the work place. Specifically, the objectives aimed are as follows:

i. To examine the relationship between managing diversity and workplace effectiveness.

ii. To investigate the relationship between age diversity and employee effectiveness in the workplace.

iii. To examine the relationship between ethnic diversity and employee efficiency in the workplace.

\section{RESEARCH HYPOTHESES}

The following alternate hypotheses will be used for the study:

$\mathbf{H}_{1}$ : There is a significant relationship between managing diversity and workplace effectiveness.

$\mathbf{H}_{2}$ : there is a significant relationship between age diversity and employee effectiveness.

$\mathbf{H}_{3}$ : there is a significant relationship between ethnic diversity and employee efficiency.

\section{LITERATURE REVIEW}

\subsection{Conceptual Framework on Managing Diversity}

Evans \& Henry (2007), said "diversity means the mixture of workforce from different sociocultural backgrounds working together in an organization". It could be seen as the features of a social grouping that reveals the degree of objectives or subjective differences existing among groups (Knippenberg \& Schippers, 2007).

Scott \& Sims (2016) defined workforce diversity "as a strategy that promotes and supports the integration of human diversity at all levels and uses focused diversity and inclusion policies and practices to guide this approach in work environment". All these definitions simply show that diversity is all about these characteristics that make us different or similar to one another. In an organizational setting, a diverse workforce consists of a mixture of employees from various genders, ages, races, ethnic backgrounds, religious beliefs, etc.

\subsection{Dimensions of Diversity}

Often diversity is distinguished along the primary, secondary and tertiary or organizational dimensions. Differences among employees can be can be categorized into two aspects; primary differences such as; age, etc. and the secondary differences such as; educational background, communication style, etc. (Aydan, 2016).

\section{Primary Dimension}

Primary Dimension: This aspect reveals the key dissimilarities among diverse individuals as well as the highest impact on initial encounters, it could be quickly detected and it also serve as a filter through which people view the world. It includes visible identity characteristics such as; gender, age, sexual orientation, physical abilities, ethnicity, race, etc. (Sayers, 2012). Powell (2011) said they are those essential unchangeable personal characteristics that exert significant lifelong impacts and they shape our basic self-image sense of identity.

\section{The Secondary Dimension}

Secondary differences such as; educational background, communication style, marital status, organizational role and position, religion, geographic location, income, work experience and work style, are those qualities that are not noticeable in the first encounter and can even change throughout different encounters. These dimensions are appear to be less visible, exert a more variable influence on personal, and add a more subtle richness to the primary dimension of diversity (Sayers, 2012). People are usually less sensitive about these aspects because they are element we have made a choice on and we have the power to change them. The secondary dimensions of diversity are referred to by organizational researchers as Experience-based diversity. This form of diversity includes a wide range of differences that are acquired, discarded, and/or modified throughout one's lifetime and as a result, are less pertinent to one's core identity.

\section{Organizational Dimension}

This dimension deal with characteristics within the organization, such as; word location, organizational structure, 
part time or full time, organizational climate or culture, status, etc. (Sayers, 2012). The basis for secondary and organizational dimensions of diversity is information processing and decision making theory. This perspective suggest that diversity when managed will have positive implications on work group outcomes since such groups will have a wide array of views, skills, and information. Educational background, functional and industrial experience are part of the competencies that one employs when undertaking a task. The ability to productively discuss and examine task related content issues grounded in a diverse set of perspectives can enhance performance.

\subsection{Factors Contributing to Increased Diversity within in the workplace}

Griffin \& Van Fleet (2014) outlined three factors that contributed to organizations becoming more diverse.

\section{i. Government Legislation and Judicial Regulations}

The government legislation and judicial decisions have force a lot of organizations to explain its recruitment strategy and hire more broadly. Unlike like before where organizations were allow to hire as the deemed fit, women could hardly even be seen in office jobs not to mention being among executives. There were issues of stereotype and prejudice that resulted in discrimination against women and other minorities. Today, organizations by regulations and law must employ people based on their qualifications.

\section{ii. Composition of the Labour Force}

The composition of the labour force is becoming more and more diverse. Organizations are recognizing that by hiring a diverse workforce, they promote the most talented people available who will improve their overall quality of their workforce and increase effectiveness? By spreading a wider net in recruiting and looking beyond the traditional sources for new employees, organizations are discovery more largely qualified and better qualified employees from different segment of the society

\section{iii. Globalization}

Globalisation is that process whereby organizations start operating in an international scale. Globalization has resulted in the removal of barriers between markets thereby, allowing a free flow of goods and services, skills and ideas. As these barriers were eliminated, organizations saw an opportunity to enlarge their operations worldwide and increase their market share in order to gain more competitive advantage over their competitors (Nwinami, 2014). Also, when organizations open offices and branches abroad, it must learn to deal with the different customs and social norms of the country where is it opening branches. As the managers and employees move from one job assignment to another across the national boundaries, organizations and their subsidiaries become more diverse.

\subsection{The Concept of Gender Diversity}

Powell (2011) defined gender as the physiological inference of a someone being either male or female, like expectations and beliefs regarding what kind of attitudes, behaviours, values, knowledge, skills, and interests areas are more suitable for or typical of one sex than the other. The study of gender diversity focuses on how individuals believe that males and females differ. These gender variations influence the manner in which individuals react to the behaviours of others in the work settings or any other group coalition. Gender diversities are visible in prejudice, stereotypes, and discrimination. In the last decades, those organizational barriers that hinder women from advancing to the top in their career have been a vital area in organizational research. Singh \& Vinnicombe (2004) in their study discovered that women are almost if not completely absent when it comes to occupying senior positions in organizations.

Although women work in organizations purporting to have policies that offers equality of pay and opportunities, and though they most of the time appear to be well qualified, the career ladder for women in large organizations appear to be often shortened, while the male ladder extends to top of the career tree. Women are often hived off into specialist or gendered positions, such as human resources- known as the 'velvet ghetto' (Gatrell \& Swan, 2008).

The economic status of women in most organizations remains lower than that of the men. This gap exists partly due to the lower average wages of workers in female intensive occupations than that of workers in male intensive occupations. Glass ceiling is not a barrier that is based on women's lack of ability to handle upper level management positions. Instead, the barrier keeps women from advancing higher in an organization because they are women. Removing the glass ceiling and other obstacles to women's success represents a major challenge to organizations. As such, those policies that promotes equality in pay and other benefits programs for women; policies that promotes equality in pay for jobs of equal value and encourage other benefit programs of special interest to women are needed in organizations.

These practices and processes do not only appear in large organizations and public service organizations but also in small and big firms, women are often absent at board level within family businesses, where sons continue to take precedence over daughters and where women's contribution is frequently marginalized. Men have thus become the 'somatic norm' in organizational roles involving management and decision making. 


\subsection{Concept of Age Diversity}

Age diversity is a shared phenomenon that is present in nearly all groupings, such as families, higher institutions, sport teams, and work or team groups with members of varying ages (Kunze, et al 2013). Explained that workforce is unique in its generational diversity, which presents new challenges to organizations attempting to attract, retain, manage, and motivate quality employees. Each generation believes that its strengths are unique and they do not enhance those of other generations (Rowe, 2010). Where age diversity is practiced, the benefits accrue both to the organization and the employees. Having an age diverse environment produces and creates better working relationships and enhances social cohesion for all.

\subsection{Concept of Ethnic Diversity}

Ethnicity could be seen as an assembly of individuals who share common cultural traditions and customary practices and also provide their members with a self-conscious identity as a nation (Sayers, 2012). Ethnic diversity implies diversity in language, religions, races and cultures. There has been an increase in multicultural workforce in the organization for utilizing greater participation and synergy to improve and increase both employee satisfaction and business performance. A moderate level of ethnic diversity has no effect on team performance in terms of business outcomes i.e. sales, profit, and market share. However, if at least the majority of team members are ethnically diverse, then more ethnic diversity has a positive impact on performance. Following the raise of diversity in recent times, there has be a raise in work groups with the intention of making increased participation to enhance employee and organizational performance as a whole. However, in as much as the nature of the composition of employees is speedily getting more and more varied in terms of ethnicity, age, gender, education, etc., similar attention has been growing with respect to the effect of these diversities in academic institutions (Watzon, 2002).

\subsection{Benefits of Diversity and Diversity Management}

Research indicates that when diversity is accepted and valued, it boost employee effectiveness, organization's productivity, and ensure the organization's continuous competiveness. Managers that are able to encourage and promote a diverse work environment invariably attract and retain valuable workforce and thus, enhance the loyalty of customers. Looking at public corporations, this also turns into a successful delivery of vital services to communities with varied wants. Loewy \& Guffey (2011) suggested three benefits of diversity. They are;

1. Work Team: In organizations, employees are sometimes group into teams. These teams are made up of people from different background. When people from different background come together in a team, it gives room for creativity, effective problem solving techniques and quick decision making.

2. Business Organization Diversity is an important bottom line business strategy organizations use to improve employees' relationship and increase their productivity. Organizations that create time and put aside resources to cultivate, harness and take advantage of diversity will experience less discrimination law suits, less union conflict and fewer government regulatory actions

3. Consumers Customer preferences are always changing. Consumers desire for organizations to have specialized products and services that will always satisfy their needs at all times. When organizations have teams made up of persons from various backgrounds and experiences, such groups are better equipped to create products that the consumers required. Having employees from different backgrounds provides the organization with array of skills and experiences in recommending ideas that are flexible in adjusting to changing customer demands (Saxena, 2014). Consumers desire to transact with organizations that respect their values and reflex themselves. Also organizations that have a wide pool of employees with skills and experience can provide service to customer in a global basis. According to Esty, et al (1995) other benefits of diversity management includes;

\section{Increased productivity}

When employees feel respected, included and valued in the organization, they become committed to its goal and hence work towards achieving the goals. Fewer lawsuits: there will be fewer lawsuits since both management and employees have been trained on how to respect and value difference and treat everyone equally without discrimination.

\section{Retention of business:}

Organizations now pay careful attention to other organizations that they transact with. Seeking out for businesses that suppose inclusion.

6. Increased market marketing capabilities: having diverse workforce can provide an organization with insight into the thinking of a wide range of customers. As markets are segmented, even the smaller market begins to gain importance. Therefore, attracting prospective customers can be the critical difference between the organization surviving or dying out.

7. The organization can become an employer of choice: as people hear of how well the company accepts and manages diversity, it grows the company's image. People want to be a part of such organization.

8. Better morale or improved morale: the ambience of the work environment can become more fun and lively 
when there is a mix of workforce.

9. Improved decision making: diverse workforce have the potential for making high quality decisions because they must deal with dissenting views before the move forward.

\subsection{Best Approaches for Managing Diversity}

Diversity management is a process that encompasses systems, policies and practices. It is creating a workplace and making it one where employees' differences and views are valued, respected and used to increase the capacity of the organization (CDMP, 2004). According to Mor Barak (2014) diversity management "refers to the voluntary organizational actions that are designed to create through deliberate policies and programs greater inclusion of employees from various backgrounds into the formal and informal organizational structures". It is recognizing how individual's similarities and differences can be organized for the good of not just the individual and the organization but for the society as a whole. Diversity management strategies can help organizations to construct a link between its internal and external aspects of work. That an organization is having or hiring a diverse workforce does not at all translate into positive benefits. Instead, managers and organizational leaders must effectively manage diversity in order to reap the benefits thereof (EU, 2015). The focus of diversity management is to maximize the ability of the entire workforce, to contribute to achievement of organizational goals (UCSF, 2012). To avoid the costs associated with ignoring diversity and to successfully manage diversity, it is important that organizations take active measures to build an inclusive culture (NIWGW, 2009). According to Oracle (2014) organizations can adopt these strategies to build an inclusive workplace are;

i. Look beyond Compliance: To build an inclusive organization, the first step is to have an understanding that diversity management is much more than just complying with the initiative of affirmative action (Oracle, 2014). Diversity management indicates a shift away from the assumptions and activities of affirmative action to inclusive management practices that embraces the similarities and differences of all the employees (UCSF, 2012). It is about building a workforce that is as diverse as the organization's customer base and utilizing those differences to ignite creativity and improve efficiency that will drive business to success.

ii. Address Diversity in Every Aspect of Talent: Management Managers should address diversity issues all through the employee's lifecycle. Diversity and inclusion topics should go beyond recruitment and selection and also extend beyond human resource to the organization as a whole. It should also be considered in every phase of talent management starting from recruitment, selection, on-boarding to workforce planning, leadership training, performance management, professional development, etc.

iii. Identify New Talent Pool: Often time, organizations only limit their recruitment to traditional new hire source such as; the university programs and industrial organizations. To make in the workplace inclusive one, organizations must enlarge its recruitment scheme to spot and inculcate new talent pools both within and outside the organization.

iv. Encourage Reverse Mentoring: The traditional idea about mentoring normally involves an experience mentor developing a subordinate mentee. On the other hand, reverse mentoring acknowledges that the junior workers also have insights which some senior employees do not have and can benefit from the junior employees (NIWGW, 2009). Management should allow the junior employees to feel valued by encouraging the senior employees to gain fresh insights and perspective from the younger employees as this can help to improve older employees' effectiveness and relevance within the organization.

v. Model Good Behaviour: Executive management should model the behaviour they expect to see in the managers and employees by living according to the values of the organization, demonstrating an inclusive behaviour and taking active part in all the initiatives that promotes diversity, inclusive and harmonious work environment (NIWGW, 2009). Executives should be models of diversity and inclusion. The fact is workers often follow the cue of their top management. Therefore, top executives should be capable of articulating the business case for diversity. Let the employees see that their top executives support diversity (Kampf, 2017).

vi. Make Diversity a Part of the Organization's Brand: Diversity and inclusion should not only be a word a mouth thing by managers should ensure to also work the talk. The society should know that the organization is one that welcomes, celebrates and utilizes differences and this is achieved by making diversity and inclusion a part of the business brand. To achieve this, management can promote volunteerism among employees, offer scholarship and internship to individuals from the underrepresented groups, etc.

\section{METHODOLOGY}

This research therefore covers one selected commercial bank in Abuja, namely Zenith Bank PLC, Abuja. Secondary data were obtained through books, journals, and internet. Empirical works of other scholars were consulted. A simple size of 133 was obtained from the population of 200 at 5\% error tolerance and $95 \%$ degree of freedom using Yamane's statistical formula 133(100\%) of the questionnaires distributed $120(90 \%)$ were returned and 13(10\%) were not returned. The questionnaire was designed in Likert scale format. The researchers conducted a pre-test on the questionnaire to ensure the validity of the instrument. One-Sample Statistics analysis 
was used to test the hypotheses.

\section{TEST OF HYPOTHESES}

Hypothesis one

$\mathrm{H}_{\mathrm{I}}$ : There is a significant relationship between managing diversity and workplace effectiveness.

$\mathrm{H}_{0}$ : There is a no significant relationship between managing diversity and workplace effectiveness

Table 1: Descriptive Table

\section{One-Sample Statistics}

\begin{tabular}{|l|l|l|r|r|}
\hline & & \multicolumn{1}{|c|}{$\begin{array}{c}\text { Std. } \\
\text { Deviation }\end{array}$} & $\begin{array}{c}\text { Std. Error } \\
\text { Mean }\end{array}$ \\
\hline $\begin{array}{l}\text { There is a significant relationship between managing diversity and } \\
\text { workplace effectiveness. }\end{array}$ & 155 & 2.54 & 1.459 & .099 \\
\hline
\end{tabular}

Source: Authors computation using SPSS

The output above tells us that there are 155 observations $(\mathrm{N})$, the mean number of managing diversiy on work place effectiveness in Zenith bank is 2.54 and the standard deviation of number is 1.459. Also the standard error of the mean (ie the standard deviation of the sampling distribution of means) is 0.99 (1.459/ square root of $155=$ 0.99).

Table 2: Summary of One Sample Test

\begin{tabular}{|l|c|c|c|}
\hline & $\mathrm{T}$ & Df & $\begin{array}{c}\text { Sig. (2- } \\
\text { tailed) }\end{array}$ \\
\hline $\begin{array}{l}\text { There is a significant relationship between managing diversity and workplace } \\
\text { effectiveness. }\end{array}$ & 15.523 & 154 & .000 \\
\hline
\end{tabular}

Source: Author's Computation using SPSS

Note: $\alpha=0.05$ (5\% level of sig)

From the t-table the second column of the output gives us the t-test value (15.523). The third column tells us that the $t$ test has 215 degrees of freedom $(155-1=154)$. The fourth column tells us the two-tailed significance (the 2-tailed $\mathrm{p}$ value).

Decision:

If $t$ calculated $\leq \mathrm{t}$ observed: reject null hypothesis, meaning there is insufficient evidence to conclude that the mean number of the test is statistically significant

$\mathrm{t}$ calculated $\geq \mathrm{t}$ observed: accept null hypothesis, meaning there is sufficient evidence to conclude that the mean number of the test is statistically significant.

From the result $t$ observed is 15.523 while $t$ calculated $=2.358$. This means $t$ calculated is less than $t$ observed $(2.358<15.523)$; hence we reject the null hypothesis, meaning there is insufficient evidence to conclude that the mean number of the test is statistically significant.

Conclusion:

Since $t$ calculated is below t observed we reject the null hypothesis and conclude There is a significant relationship between managing diversity and workplace effectiveness.

Hypothesis II:

Ho: $\quad$ There is no significant relationship between age diversity and employee effectiveness.

$\mathbf{H}_{1}$ : $\quad$ There is a significant relationship between age diversity and employee effectiveness.

Table 3: Descriptive Table

One-Sample Statistics

\begin{tabular}{|l|r|r|r|r|}
\hline & & & $\begin{array}{c}\text { Std. } \\
\text { Deviation }\end{array}$ & $\begin{array}{c}\text { Std. Error } \\
\text { Mean }\end{array}$ \\
\hline $\begin{array}{l}\text { There is a significant relationship between age diversity and employee } \\
\text { effectiveness. }\end{array}$ & 155 & 2.13 & 1.429 & .097 \\
\hline
\end{tabular}

Source: Authors computation using SPSS

From the output above there are 155 observations $(\mathrm{N})$, the mean number of Age diversity on employee effectiveness in Zenith bank is 2.13 with the standard deviation of 1.429. Also the standard error of the mean (ie the standard deviation of the sampling distribution of means) is $0.97(1.429$ / square root of $155=0.97)$. 


\section{Table 4:Summary of One Sample Test}

\begin{tabular}{|l|c|c|c|}
\hline $\begin{array}{l}\text { There is a significant relationship between age diversity and employee } \\
\text { effectiveness. }\end{array}$ & 11.644 & 154 & $\begin{array}{c}\text { Sig. (2- } \\
\text { tailed) }\end{array}$ \\
\hline
\end{tabular}

Source: Author's Computation using SPSS, 2018

Note: $\alpha=0.05$ ( $5 \%$ level of sig)

From the t-table the second column of the output gives us the t-test value (11.644). The third column tells us that the $t$ test has 215 degrees of freedom $(155-1=154)$. The fourth column tells us the two-tailed significance (the 2 tailed $\mathrm{p}$ value).

\section{Decision:}

If $t$ calculated $\leq \mathrm{t}$ observed: reject null hypothesis, meaning there is insufficient evidence to conclude that the mean number of the test is statistically significant

$\mathrm{t}$ calculated $\geq \mathrm{t}$ observed: accept null hypothesis, meaning there is sufficient evidence to conclude that the mean number of the test is statistically significant.

From the result $\mathrm{t}$ observed is 11.644 while $\mathrm{t}$ calculated $=2.358$. This means $\mathrm{t}$ calculated is less than $\mathrm{t}$ observed $(2.358<11.644)$; hence we reject the null hypothesis, meaning there is insufficient evidence to conclude that the mean number of the test is statistically significant.

\section{Conclusion:}

Since t calculated is below t observed we reject the null hypothesis and there is a significant relationship between age diversity and employee effectiveness.

Hypothesis 3:

$\mathbf{H}_{0}$ : there is no significant relationship between ethnic diversity and employee efficiency.

$\mathbf{H}_{1}$ : there is a significant relationship between ethnic diversity and employee efficiency.

Table 5: Descriptive Table

\section{One-Sample Statistics}

\begin{tabular}{|l|r|r|r|r|}
\hline & $\mathrm{N}$ & Mean & $\begin{array}{c}\text { Std. } \\
\text { Deviation }\end{array}$ & $\begin{array}{c}\text { Std. Error } \\
\text { Mean }\end{array}$ \\
\hline $\begin{array}{l}\text { There is a significant relationship between ethnic diversity and } \\
\text { employee efficiency. }\end{array}$ & 155 & 5.52 & 1.278 & .188 \\
\hline
\end{tabular}

Source: Authors computation using SPSS

The output above tells us that there are 155 observations $(\mathrm{N})$, the mean number of ethnic diversityon employee efficiency in Zenith bank is 5.52 with standard deviation of 1.278. Again the standard error of the mean (ie the standard deviation of the sampling distribution of means) is $0.188(1.278$ / square root of $155=0.188)$.

Table 6:Summary of One Sample Test

\begin{tabular}{|l|c|c|c|}
\hline & $\mathrm{t}$ & Df & $\begin{array}{c}\text { Sig. (2- } \\
\text { tailed) }\end{array}$ \\
\hline $\begin{array}{l}\text { There is a significant relationship between ethnic diversity and employee } \\
\text { efficiency. }\end{array}$ & 8.077 & 154 & .000 \\
\hline
\end{tabular}

Source: Author's Computation using SPSS, 2018

Note: $\alpha=0.05(5 \%$ level of sig)

From the t-table the second column of the output gives us the t-test value (8.077). The third column tells us that the $t$ test has 154 degrees of freedom $(155-1=154)$. The fourth column tells us the two-tailed significance (the 2 tailed $\mathrm{p}$ value).

\section{Decision:}

If $t$ calculated $\leq \mathrm{t}$ observed: reject null hypothesis, meaning there is insufficient evidence to conclude that the mean number of the test is statistically significant

$t$ calculated $\geq t$ observed: accept null hypothesis, meaning there is sufficient evidence to conclude that the mean number of the test is statistically significant.

From the result $t$ observed is 8.077 while $t$ calculated $=2.423$. This means $t$ calculated is less than $t$ observed $(2.423$ $<8.077$ ); hence we reject the null hypothesis, meaning there is insufficient evidence to conclude that the mean number of the test is statistically significant.

\section{Conclusion:}

Since $t$ calculated is below $t$ observed we reject the null hypothesis and conclude that there is a significant relationship between ethnic diversity and employee efficiency. 


\section{CONCLUSION}

The research highlighted certain diversity factors like ethnicity as serious obstacles to effective implementation of HRM Practices but the findings generally depicted a positive response towards workplace diversity in the organization and the results are not biased since different results are likely to be generated from different environmental settings. In conclusion, I would like to acknowledge that, as a manager I have spent a number o f years focusing on ensuring representation without paying much attention to the development and harnessing of individual talent and potential. The results are glaring. Improvement in demographic representation has been achieved and the represented but previously disadvantaged groups remain in lower ranks, with only one or two in management or senior positions.

It is clear from this research that wage differentials and stereotype, prejudice, biases between genders do exist in the African Culture against women in the society and minority especially certain sexual orientations like gays. The study findings showed that women do not hold low status jobs but majority of the men continue to hold top executive posts implying wage differentials is likely to exist between genders in top levels. This could be attributed by the fact that most women are in the childbearing stage and up bringing stage preventing majority to offer total career commitment and limiting majority climb to top executive positions in their career unlike their male counterparts who suggested that full time spent in the home for a working women is three (3) times that spent by a man. The traditional perception of men leadership in the society that is highly respected in top executive posts is another contribution since the study reveals non acceptance of male dominated culture influence in the organization decision making. In relation to HRM Practices they are ethically and fairly implemented in the organization but promotions and raises provided are not commensurate with time, services and qualifications rendered. However it is important to continually implement mentoring and succession planning and stick to Western official language in public institution unlike its African negative perception.

\section{RECOMMENDATIONS}

The research recommendation in relation to demographic factors relates to the needs of every employees that the management need to address by recognizing importance of measuring the tenure of members on the team; as individuals get to know each other better, the negative effects of diversity often subside. Besides the HRM Strategies to change groups should be developed since work group diversity can lead to short-term, increased conflict among members, focused training with an external facilitator may help the group to achieve higher levels of workplace in a shorter time. Training can target methods for raising, discussing and resolving difficult interpersonal, business and/or team-related process issues.

To build strong upcoming generation and workforce it is important for the organization to promote mentoring programmes in order to transfer knowledge and experience between generations and to ensure skills are passed on to the managers since the young have original outlook, knowledge and energy but older employees have special knowledge and relational skills based on experience and can be an asset for the organization. Flexible schedules should be continually ensured for working mothers who have heavy responsibilities of care and upbringing children to facilitate the skilled female workers so as to continually overcome the challenges of mismatch of jobs and skill gap globally as result of labour turnover and obsolete talents and skills.

A successful diversity strategy must address organizational culture change to create a work environment that nurtures teamwork, participation and cohesiveness characteristics of a „collective" (versus individualistic) organizational culture starting with a visioning exercise for change that specifically identifies what success in a multicultural organization might look like. A diversity council with credible people from a cross-section of functions should be charged with creating a business diversity strategy and serving as a resource. Diversity should be strategically integrated with the business objectives.

\section{REFERENCE}

Argocs, Carol/Burr, Catherine (1996): Employment Equity, Affirmative Action and Managing Diversity Assessing the Differences: International Journal of Manpower

Cox, Jr. T. (2001), Creating the Multicultural organization: A Strategy for Capturing the Power of Diversity, Jossey-Bass, San Francisco, pp.3-16.

Knouse Stephen B., Alvin \& Patricia Smith, (2008), Issues in Diversity Management, Internal Report Number 0508, Department of Management, B.I. Moody III College of Business Administration, University of Louisiana at Lafayette.

Esty, Katharine, Richard Griffin, and Marcie Schorr-Hirsh (1995). Workplace diversity. A manager's guide to solving problems and turning diversity into a competitive advantage. Avon, MA: Adams Media Corporation.

Gareth R. Jones and Jennifer M. George (2008) Contemporary Management, Published by McGraw-Hill Companies.

Hanappi-Egger, E.\&, Ukur, G. (2011): Challenging Diversity Management: on the meaning of cultural context: the Case of Kenya. 7th Critical Management Studies Conference, Nepal, Italian, 11.07.-13.07 
Hayles, Robert (1992). Costs and Benefits of Integrating Persons from Diverse Cultures in Organization. Conference Paper presented on 20th International Congress of Applied Psychology, Edinburgh, Scotland, July 25-31.

Hogg, M.A., Terry, D.J. and White, K.M. 1995. A Tale of Two Theories: A Critical Comparison of Identity Theory with Social Identity Theory. Social Psychology Quarterly, Vol. 58, No. 4.

Johnson, W. B., \& Packer, A.E. (1987). Workforce 2000: Work and Workers for the 21st Century, Indianapolis: Hudson Institute.

Kelly, Erin/Dobbin Frank (1998): How Affirmative Action Became Diversity Management. Employer Response to Antidiscrimination Law 1961 to 1996. In American Behavioural Scientist 41 (7): 960-984.

Mathis, R. L., and J.H. Jackson. (2004). Human Resource management. Singapore: Thomson Asia. Volume $7 \cdot$ Number $2 \cdot$ Summer 2009.

Kreitz, P. A. 2008. Best Practices for Managing Organizational Diversity. The Journal of Academic Librarianship, March 2008, Volume 34, Number 2, pages 101-120

Robinson, Kary-Siobhan, (2002). U.S. Must Focus on Diversity or Face Decline in Competitiveness. The Society for Human Resource Management (SHRM). Available on the World Wide Web at http://www.shrm.org. Date visited, February 8, 2002. R. Roosevelt Thomas, Jr., Building on the promise of diversity, how we can move to the next level in our workplaces, our communities and our society.

Rachele, Jude S. (2010): Equality, Diversity \& Human Rights: Driving Culture Change through Innovative Governance. Kin stone Business School UK, Summer Conference Paper Sorenze, France.

Thomas, D. A. and R. J. Ely (1996). 'Making Differences Matter: A New Paradigm for diversity Management', Harvard business Review, September-October, pp. 79-90.

Tracy, R.L. \& David E.M. (2011). Choosing workers ${ }^{e e}$ Qualifications: No Experience Necessary? International Economic Review, 34(3), 479-502.

The World Bank, (2002), Reforming Public Institutions and Strengthening Governance, Public Sector Group, Poverty Reduction and Economic Management (PREM) Network, Washington DC

Ziller, R. c. (1972). Homogeneity and Heterogeneity of Group Membership, In C.G. Mc Clintock, (ed.), Experimental Social Psychology, New York, pp. 385-441. 